\title{
Study on the Spatial Connection of Beijing Tianjin Hebei Urban Agglomeration
}

\author{
Wang Hongmei ${ }^{1 *}$, Lu Zhihui ${ }^{1}$ \\ ${ }^{1}$ School of Economics and Management, Beijing Jiaotong University, Beijing, 100044, China
}

\begin{abstract}
The importance of close cooperation among cities can be seen from the development experience of mature urban agglomerations in the world. Compared with the Yangtze river delta and the Pearl River Delta urban agglomeration, cities in Beijing Tianjin Hebei urban agglomerations are in poor connection. This paper studies the internal linkages of Beijing Tianjin Hebei Urban Agglomerations, and finds that: in recent years, the overall spatial linkages of the urban agglomerations have been several times higher than that in 2007, but they show the characteristics of geographically "dense in the South and sparse in the north"; the main connection tracks within the urban agglomerations are roughly "inverted L", that is, the connection of "Beijing-Tianjin", "Beijing-Baoding-Shijiazhuang" and "Xingtai-Handan".
\end{abstract}

\section{Introduction}

The formation and healthy development of world-class urban agglomerations with different development modes all convey a truth: the importance of close cooperation among cities in urban agglomerations ${ }^{1}$. The gap between Beijing Tianjin Hebei Urban Agglomeration (Hereinafter referred to as "BTA Agglomeration") and the other two urban agglomerations (Yangtze river delta and Pearl River Delta urban agglomeration) is reflected in many aspects, such as economic level, evolution stage, integration state, and competitiveness of BTH Agglomeration is also weaker correspondingly. The important reason for these situations lies in the unreasonable spatial connection structure of urban agglomerations ${ }^{2}$. The essential attribute of regional economy is spatial dependence ${ }^{3}$. Scientific quantification and improvement of intercity linkages promote the coordinated development of urban agglomerations and the process of regional integration ${ }^{4}$. The main linkages between cities can be divided into five types: nature, economy, technology, society and administration, each of which can be divided into various forms. The secondary classification of economic linkages includes linkages of infrastructure, trade, industry and capital. This paper focuses on linkages of economy ${ }^{5}$.

This paper innovatively selects the data of 2007(No high-speed rail), 2013(High speed railway began service) and 2017(After the coordinated development of Beijing, Tianjin and Hebei has become a national strategy, Anyang has been included in the scope of BTA Agglomeration) to study the spatial connection structure of urban agglomeration. In addition, this paper selects the provincial capital cities around the city cluster, and brings them into the research scope, thus breaking the idea of only limiting the perspective within the city cluster, and can more directly show the importance of administrative divisions.

\section{Research area and research method}

\subsection{Research area}

In February 2016, The national economic and social development plan of Beijing, Tianjin and Hebei during the 13th Five Year Plan period specified that Beijing Tianjin Hebei Urban Agglomeration covers Beijing, Tianjin, 11 cities in Hebei province and Anyang in Henan province. This is the basis to determine the scope of this study. The specific study area is shown in Figure 1.

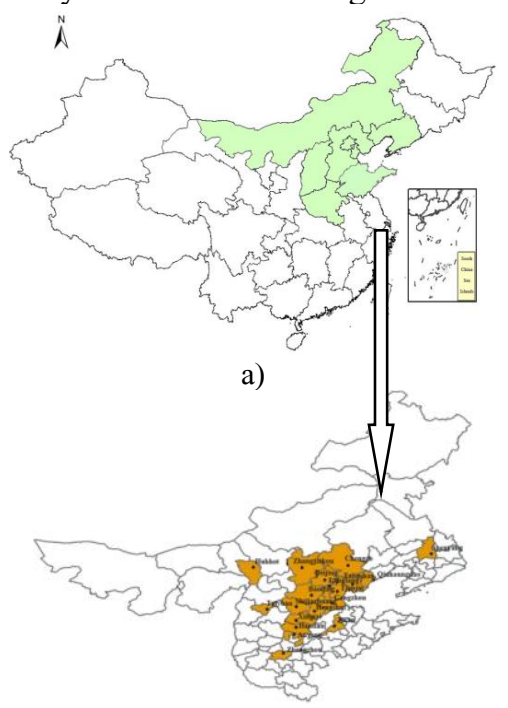

b)

Fig. 1. Distribution of Beijing Tianjin Hebei Urban Agglomeration and its surrounding areas.

* Corresponding author: hmwang@bjtu.edu.cn 


\subsection{Research Methods}

The research methods of intercity connection mainly include urban flow model and gravity model6-8. In this paper, the improved gravity model is selected according to the actual content.

Gravity model is often used in the study of economic geography. The traditional gravity model of economic connection is shown in formula (1):

$$
R_{i j}=\frac{\sqrt{\left(P_{i} V_{i}\right)\left(P_{j} V_{j}\right)}}{d_{i j}^{2}}
$$

$\mathrm{R}_{\mathrm{ij}}$ is the economic connection volume of region $\mathrm{i}$ and $j ; P_{i}, P_{j}$ represent the population of the corresponding regions; $V_{i}$ and $V_{j}$ represent the total amount of regional economy respectively, generally expressed in GDP; $d$ indicates the distance between the two cities.

In order to measure the spatial connection of BTH Agglomeration more accurately, this paper revises the economic quality and distance respectively, and adds the economic connection coefficient in the formula.

The calculation formula of the strength of the connection between cities is modified with reference to the universal gravity formula, as follows:

$$
R_{i j_{i}}=k_{i j} \frac{M_{i} \times M_{j}}{d_{i j}{ }^{2}}, \quad R_{i j}=R_{i j_{i}}+R_{i j_{j}}, \quad k_{i j}=\frac{M_{i}}{M_{i}+M_{j}}
$$

$\mathrm{R}_{\mathrm{ij}}$ indicates the strength of intercity connection, $\mathrm{R}_{\mathrm{ij}}$ is the economic effect intensity of $i$ city on $j$ City ; $\mathrm{M}_{\mathrm{i}}$ and $\mathrm{M}_{\mathrm{j}}$ indicate the comprehensive development quality of cities; $d_{i j}$ is the economic distance between the two cities, "2" in denominator is distance attenuation coefficient.

\section{Calculation and analysis of connection volume}

\subsection{Quality of urban comprehensive development}

The traditional indicators to measure the quality of urban development are modified. In this paper, from the three aspects of population quality and structure, economic scale and structure, and social development, 14 indicators are selected to measure the quality of urban comprehensive development9. According to the principal component analysis10, the weight of each index is calculated as shown in Table 1. Limited to space, the specific calculation process is not listed.

Table1. Index weight of economic quality

\begin{tabular}{|c|c|}
\hline Index & Weight \\
\hline Total urban population (10000) & 0.055 \\
\hline $\begin{array}{c}\text { Proportion of employees in the tertiary } \\
\text { industry (\%) }\end{array}$ & 0.083 \\
\hline Urbanization rate (\%) & 0.074 \\
\hline GDP (100 million yuan) & 0.084 \\
\hline Fixed assets investment (100 million yuan) & 0.083 \\
\hline $\begin{array}{c}\text { General budget revenue of local finance (100 } \\
\text { million yuan) }\end{array}$ & 0.080 \\
\hline
\end{tabular}

\begin{tabular}{|c|c|}
\hline Proportion of secondary industry (\%) & 0.034 \\
\hline Proportion of tertiary industry (\%) & 0.067 \\
\hline Per capita year-end deposit balance (yuan) & 0.072 \\
\hline Total number of hospital beds & 0.081 \\
\hline Number of doctors per 10000 people & 0.070 \\
\hline Number of college students per 10000 & 0.054 \\
\hline $\begin{array}{c}\text { Added value of transportation, warehousing } \\
\text { and post and Telecommunications (100 } \\
\text { million yuan) }\end{array}$ & 0.081 \\
\hline Total social consumption (100 million yuan) & 0.083 \\
\hline
\end{tabular}

According to the values and weights of indicators in Table 1, the comprehensive development quality of each city is calculated and shown in Table 2. It can be seen that the level of economic development of BTA Agglomeration is highly polarized. Beijing and Tianjin are far ahead in the development, while most other cities are relatively backward and low in economic quality, showing a condition of overall imbalance.

Table2. Economic quality of Beijing Tianjin Hebei Urban Agglomeration and its surrounding provincial capitals

\begin{tabular}{|c|c|c|c|}
\hline City & 2007 & 2013 & 2017 \\
\hline Beijing & 1.878 & 3.319 & 4.085 \\
\hline Tianjin & 1.193 & 2.189 & 2.582 \\
\hline Shijiazhuang & 0.656 & 1.206 & 1.639 \\
\hline Chengde & 0.260 & 0.458 & 0.593 \\
\hline Zhangjiakou & 0.251 & 0.511 & 0.800 \\
\hline Qinhuangdao & 0.547 & 0.678 & 0.872 \\
\hline Tangshan & 0.435 & 1.013 & 1.397 \\
\hline Langfang & 0.346 & 0.446 & 0.862 \\
\hline Baoding & 0.224 & 0.514 & 1.007 \\
\hline Cangzhou & 0.246 & 0.627 & 1.070 \\
\hline Hengshui & 0.261 & 0.452 & 0.797 \\
\hline Xingtai & 0.199 & 0.433 & 0.778 \\
\hline Handan & 0.272 & 0.615 & 1.046 \\
\hline Anyang & 0.065 & 0.288 & 0.530 \\
\hline Shenyang & 0.883 & 1.517 & 1.755 \\
\hline Huhhot & 0.543 & 1.013 & 0.991 \\
\hline Taiyaun & 0.847 & 1.517 & 1.712 \\
\hline Zhengzhou & 0.838 & 1.459 & 2.120 \\
\hline Jinan & 0.877 & 1.404 & 1.699 \\
\hline
\end{tabular}

\subsection{Distance between cities}

The distance here is calculated based on highway and railway time and money costs. First, calculating the weight of each mode according to the volume of passenger and freight traffic, then calculating the time and fare of the two transportation modes, and finally calculating the economic distance. The calculation results of weight are shown in Table 3: 
Table3. Weight of railway and highway transportation

\begin{tabular}{|c|l|l|l|}
\hline Mode of transport & 2007 & 2013 & 2017 \\
\hline railway transport & 0.118 & 0.139 & 0.146 \\
\hline road transport & 0.882 & 0.861 & 0.854 \\
\hline
\end{tabular}

Limited to the space, the calculated economic distance matrices are not listed.

\subsection{Connections between cities}

\subsubsection{Calculation of connection volume}

Based on the above calculation results, the amount of economic ties between cities and the total amount of external economic ties of each city can be get, as shown in Table 4. The overall connection of urban agglomeration in 2017 has been several or even more than ten times larger than that in 2007.

Table4. Strength of economic ties between Beijing Tianjin Hebei Urban Agglomeration and surrounding provincial capitals

\begin{tabular}{|c|c|c|c|}
\hline City & 2007 & 2013 & 2017 \\
\hline Beijing & 3.408 & 8.750 & 21.030 \\
\hline Tianjin & 2.438 & 6.374 & 12.237 \\
\hline Shijiazhuang & 0.642 & 2.230 & 4.970 \\
\hline Chengde & 0.142 & 0.418 & 0.836 \\
\hline Zhangjiakou & 0.137 & 0.682 & 1.229 \\
\hline Qinhuangdao & 0.346 & 0.858 & 1.471 \\
\hline Tangshan & 0.652 & 2.254 & 4.580 \\
\hline Langfang & 1.895 & 4.824 & 11.667 \\
\hline Baoding & 0.355 & 1.620 & 4.234 \\
\hline Cangzhou & 0.403 & 2.046 & 4.792 \\
\hline Hengshui & 0.298 & 0.998 & 2.534 \\
\hline Xingtai & 0.316 & 1.531 & 4.383 \\
\hline Handan & 0.306 & 1.705 & 5.323 \\
\hline Anyang & 0.077 & 0.766 & 2.050 \\
\hline Shenyang & 0.141 & 0.378 & 0.533 \\
\hline Huhhot & 0.085 & 0.277 & 0.481 \\
\hline Taiyaun & 0.302 & 0.943 & 1.874 \\
\hline Zhengzhou & 0.181 & 0.699 & 1.601 \\
\hline Jinan & 0.373 & 1.414 & 2.487 \\
\hline
\end{tabular}

According to Table 4, we can make specific analysis on the amount of connection, and Figure 2 shows the change trend of the total amount of connection of BTA Agglomeration. It can be seen that the growth rate among the three periods is relatively large, and the trend line of the proportion of the internal connection volume of BTH Agglomeration in the overall research area shows a break in 2013, which indicates that the traffic factor of highspeed rail in the surrounding provincial capitals in 2013, and the policy factor that coordinated development had not become the national strategy led to the relative decline of the internal connection volume of BTA Agglomeration in 2013.

In Table 5, the coefficient of variation of BTH Agglomeration exceeded 1 only in 2007, and has been declining since then, which shows that the gaps between the internal cities of BTH Agglomeration are narrowing, and the gaps are smaller than that of the overall research area.

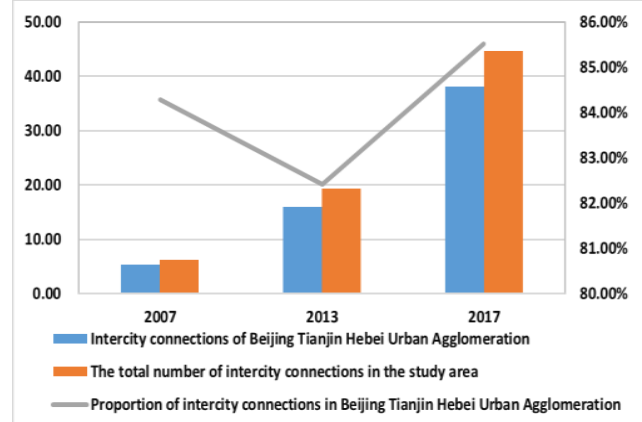

Fig. 2. Total amount and proportion of economic ties in 2007,2013 and 2017

Table5. Coefficient of variation

\begin{tabular}{|c|c|c|}
\hline \multirow{2}{*}{ Year } & \multicolumn{2}{|c|}{ Coefficient of variation } \\
\cline { 2 - 3 } & $\begin{array}{c}\text { Beijing Tianjin Hebei Urban } \\
\text { Agglomeration }\end{array}$ & $\begin{array}{c}\text { Overall } \\
\text { study area }\end{array}$ \\
\hline 2007 & 1.201 & 1.341 \\
\hline 2013 & 0.941 & 1.067 \\
\hline 2017 & 0.925 & 1.081 \\
\hline
\end{tabular}

\subsubsection{Level of connection volume}

According to the natural breaks method in ArcGIS, the hierarchical distribution of connections can be obtained, and the main connection tracks can be expressed, as shown in Figure 3. The connection shows the characteristics of "dense in the South and sparse in the north"; the main connection track generally presents the "inverted L" type, namely the connection of "Beijing-Tianjin", "BeijingBaoding-Shijiazhuang" and "Xingtai-Handan".

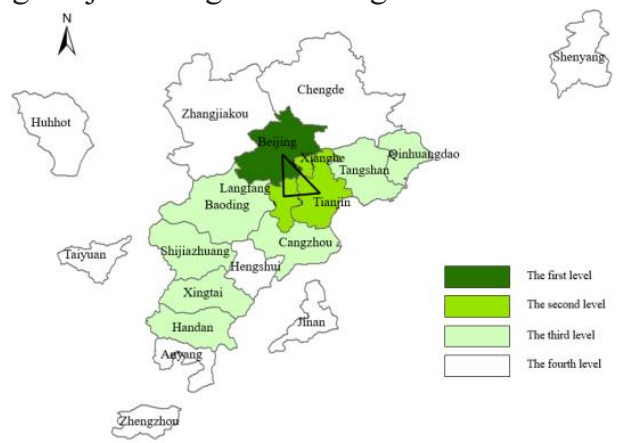

a) 2007

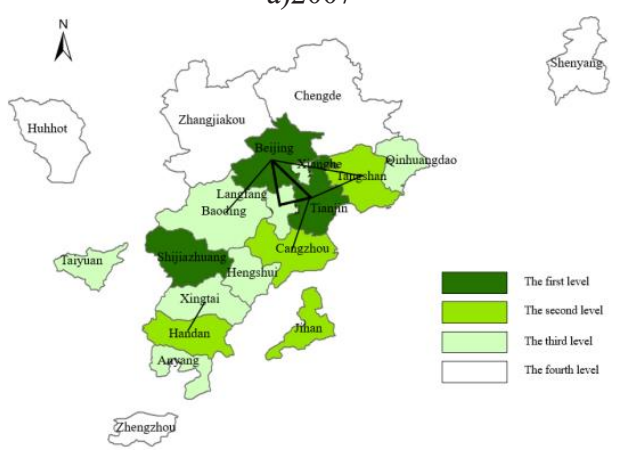

b)2013 


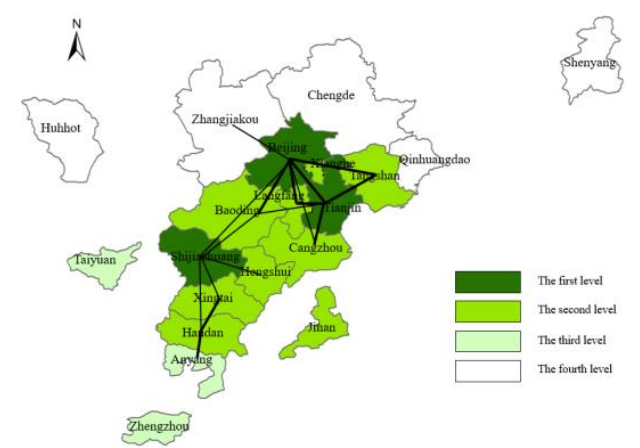

c) 2017

Fig. 3. Distribution of economic ties

\subsubsection{Connection direction and membership}

The primary and secondary radiation and receiving cities of each city are identified according to the amount of connection in 2017 , so as to analyze the main connection direction of each city. The radiation effect shows a strong regional neighborhood directivity, while the accepted connection has a strong central city directivity.

Economic subordination degree is an indicator to measure the dependence of surrounding cities on the central city, and also an indicator to measure the direction of the city's external connection, which can reflect the contribution of the central city in the economic connection. The calculation formula of economic subordination degree is shown in formula (3):

$$
F_{i j}=\frac{R_{i j}}{\sum_{j=1}^{m} R_{i j}}
$$

$m$ represents the number of cities other than themselves, $F_{i j}$ is the subordination degree of $i$ city to $j$ city.

The subordination degree of each city to the central city is shown in Table 6 and Figure 4.

Table6. Subordination degree of each city

\begin{tabular}{|c|c|c|c|}
\hline membership & Beijing & Tianjin & Shijiazhuang \\
\hline Beijing & - & $22.31 \%$ & $3.13 \%$ \\
\hline Tianjin & $38.35 \%$ & - & $2.69 \%$ \\
\hline Shijiazhuang & $13.29 \%$ & $6.65 \%$ & - \\
\hline Chengde & $37.27 \%$ & $13.41 \%$ & $2.85 \%$ \\
\hline Zhangjiakou & $46.01 \%$ & $11.27 \%$ & $5.80 \%$ \\
\hline Qinhuangdao & $23.28 \%$ & $16.43 \%$ & $2.57 \%$ \\
\hline Tangshan & $32.54 \%$ & $29.66 \%$ & $2.06 \%$ \\
\hline Langfang & $72.35 \%$ & $15.61 \%$ & $1.08 \%$ \\
\hline Baoding & $31.41 \%$ & $13.54 \%$ & $15.82 \%$ \\
\hline Cangzhou & $19.44 \%$ & $35.99 \%$ & $4.57 \%$ \\
\hline Hengshui & $11.65 \%$ & $35.99 \%$ & $4.57 \%$ \\
\hline Xingtai & $3.76 \%$ & $1.69 \%$ & $15.08 \%$ \\
\hline Handan & $3.33 \%$ & $1.88 \%$ & $8.99 \%$ \\
\hline Anyang & $3.35 \%$ & $1.83 \%$ & $6.36 \%$ \\
\hline Shenyang & $21.77 \%$ & $14.36 \%$ & $4.44 \%$ \\
\hline Huhhot & $24.46 \%$ & $8.36 \%$ & $6.20 \%$ \\
\hline Taiyaun & $12.31 \%$ & $6.67 \%$ & $23.94 \%$ \\
\hline
\end{tabular}

\begin{tabular}{|c|c|c|c|}
\hline Zhengzhou & $8.66 \%$ & $5.70 \%$ & $9.05 \%$ \\
\hline Jinan & $13.99 \%$ & $13.43 \%$ & $9.37 \%$ \\
\hline
\end{tabular}

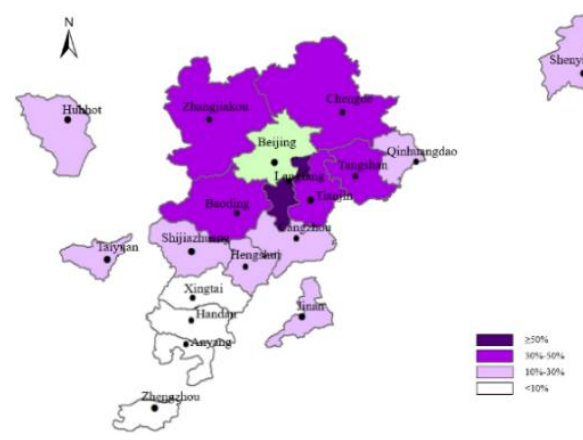

a) The economic hinterland of Beijing in 2017

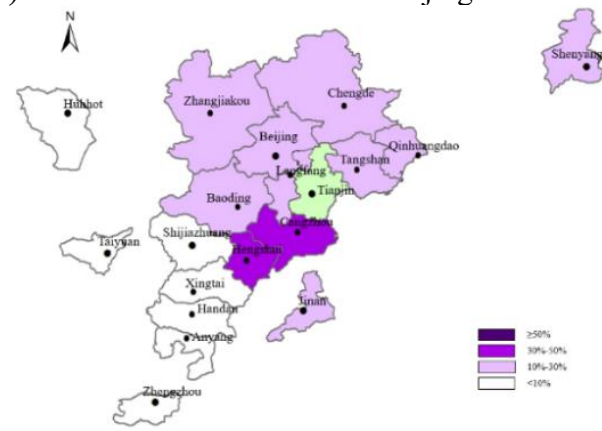

b) The economic hinterland of Tianjin in 2017

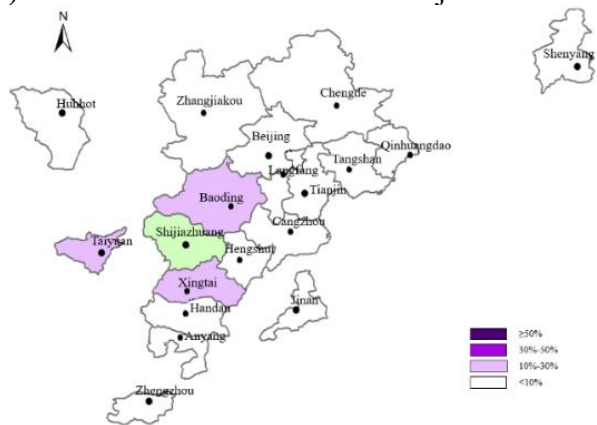

c) The economic hinterland of Shijiazhuang in 2017

Fig. 4. Geographical distribution of economic hinterland of central city

\section{Conclusions and recommendations}

The main conclusions are as follows: (1) the overall spatial connections of BTA Agglomeration in 2017 have been several times higher than that in 2007, with the characteristics of "dense in the South and sparse in the north"; (2) the main central connection cities within BTA Agglomeration are Beijing, Tianjin and Shijiazhuang; (3) the main connection tracks roughly present the "inverted L" type, namely the connection of "Beijing-Tianjin", "Beijing-Baoding-Shijiazhuang" and "Xingtai-Handan".

The following suggestions are put forward: (1) Strengthen the central position of the central cities and give full play to the complementary functions of secondary central cities. (2) Establish more transportation infrastructure to strengthen the transportation tracks between the weak areas and the central cities. (3) Pay attention to the development along the connection axes, which are consistent with the existing policy planning, and can better improve the connection level. 


\section{Acknowledgements}

This article is supported by the fund project: Beijing Municipal Education Commission scientific research and postgraduate training co-construction project "Research on urban traffic development strategy in Beijing in the context of new urbanization".

\section{Reference}

1. N. Wang, Journal of Technical Economics \& Management (2005)

2. J. Lu, E. Zhu, Journal of Capital University of
Economics and Business (2014)

3. J. Sun, Reform (2014)

4. M. Zhao, J. Wei, K. Wu, Urban Planning Forum (2014)

5. C. Gu, Beijing: The Commercial Press (1992)

6. Y. Chen, J. Liu, Geographical Research (2002)

7. S. He, C. Li, G. Zhou, Economic Geography (2014)

8. L. Ye, X. Ou, Urban Development Studies (2012)

9. H. Zhao, Data (2009)

10. K. Xiao, M. Xiang, M. Feng, Resources and Environment in the Yangtze Basin (2017) 